\title{
A ACELERAÇÃo do TEMPO E O DECLíNIO DA EXPERIÊNCIA NA CONTEMPORANEIDADE
}

\author{
The acceleration of time and the decline of contemporary \\ experience
}

RESUMO Com base no conceito de tempo social, apresentado por Nobert Elias, este ensaio investiga os impactos da acentuada aceleração temporal vivenciada na contemporaneidade, a partir de três secções distintas. Na primeira, discutiremos como o ethos da sociedade ocidental - que superestima as experiências ancoradas no "aqui-agora", no provisório e no instantâneo - tem provocado novas reconfigurações da subjetividade, comprometendo padrões significativos na relação tridimensional estabelecida pelo passado, presente e futuro. Na segunda, entenderemos como o desenvolvimento dos processos comunicativos, com ênfase nos recursos digitais, subtrai os sentidos, e, por conseguinte, contribui para a aceleração da percepção do tempo. Para esse propósito, a Teoria da Mídia, apresentada por Harry Pross, será articulada à Teoria da tecnoimagem, evidenciada por Vilém Flusser. Por fim, na terceira seção, serão exibidas reflexões da experiência cotidiana em consonância com o arcabouço teórico de Hartmut Rosa, representante da Teoria Crítica da Sociedade repensada sob a ótica da temporalidade.

Palavras chaves: Tempo social. ExperiÊnCIA. ACEleração E CONTEMPORANEIDADE.

ABSTRACT Based on the concept of social time, presentation by Nobert Elias, this essay investigates the impacts of temporal acceleration experienced in the contemporary world from three different sections. In the first, we will discuss how the Western society ethos - which overestimates as anchored experiences not here-now, without provision and without snapshot - has provoked new reconfigurations of subjectivity, compromising significant patterns in the three-dimensional relationship established by past, present and future. In the second, we understand how the development of communicative processes, with an emphasis on digital resources, subtract the senses, and, consequently, contribute to an acceleration of the perception of time. For this purpose, a Theory of the Media, presented by Harry Pross, will be articulated to the Techno-image Theory, evidenced by Vilém Flusser. Finally, in the third section, reflections of daily experience are presented in consonance with the theoretical framework of Hartmut Rosa, representative of the Critical Theory of Society rethought from the viewpoint of temporality.

KEY-WORDS: SOCIAL TIME. EXPERIENCE. ACCELERATION AND CONTEMPORANEITY.

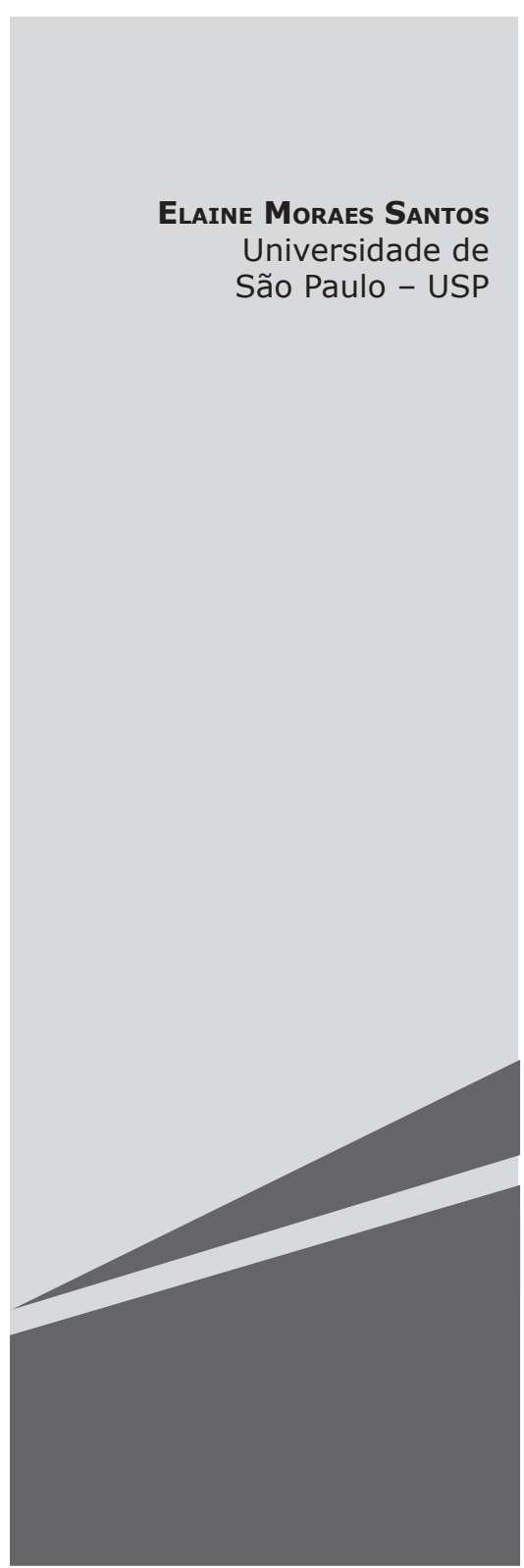




\section{INTRODUÇão}

C ompreender como as pessoas se relacionam com o tempo na sociedade contemporânea implica investigação sobre aspectos históricos, sociais e subjetivos que contribuem, ou não, para uma experiência autêntica nos dias atuais. Para trazer à tona alguns questionamentos acerca do assunto, é fundamental conceituar qual a perspectiva de tempo que estamos tratando neste ensaio. Desde o início da história do ocidente, a questão do tempo circula nos debates de uma longa lista de intelectuais e pensadores, que buscam defini-lo a partir de diferentes olhares. A ciência exata, por exemplo, entende que a grandeza física rudimentar desse fenômeno é passível de ser quantificada, medida, controlada e determinada. Em contraposição, uma abordagem ontológica, filosófica ou sociológica trará aspectos mais subjetivos, qualitativos, históricos e imensuráveis a respeito da questão. Na busca de reduzir a cisão entre esses saberes, a concepção de tempo aqui adotada permite uma compreensão do fenômeno a partir das proposições apresentadas por Elias (1984), que preconiza o rompimento dessa dicotomia histórica por meio da concepção sociológica do tempo social. Para o autor, a impossibilidade de coesão entre esses diversos conhecimentos se dá na medida em que tais correntes buscam compreender o fenômeno como algo puramente externo ou interno ao ser humano, sem levar em consideração a relação homem-natureza. Partindo dessa relação como pressuposto, Elias (1984) conceitua o tempo com base em sua função social reguladora, que busca o "relacionamento de posições ou segmentos pertencentes a duas ou mais sequências de acontecimentos" (ELIAS, 1984, p. 13). Desse modo, o tempo passa a ser entendido como uma instituição padronizada de acordo com as necessidades de organização e interação de determinada sociedade. Para a maneira de conceber ou vivenciar o tempo, não é uma questão biológica ou metafísica, mas se trata de uma dimensão social que muda ao longo das gerações. No calendário maia (séc. $\vee$ a.C.), por exemplo, o tempo era concebido como cíclico e finito. Ao observar os fenômenos periódicos da natureza (o movimento das marés, o dia e noite, as estações climáticas e assim por diante), os pensadores da antiguidade acreditavam em um movimento circular e repetitivo do tempo. A ideia de um tempo linear surgiu a posteriori sendo difundido, principalmente, pela religião cristã, ${ }^{1}$ por um percurso histórico que envolve o início em Gênesis e um fim em Apocalipse. Posteriormente, com o desenvolvimento das sociedades industriais, a percepção do tempo passa a ser controlada e medida por instrumentos cada vez mais sofisticados, criando nos indivíduos não apenas uma noção de linearidade como de tridimensionalidade simbólica ancorada por um passado, presente e futuro. Contudo, conforme veremos a seguir, essa relação tridimensional estaria distorcida nos dias de hoje e uma acentuada aceleração temporal vivenciada na contemporaneidade, fixada primordialmente do tempo presente, estaria provocando um empobrecimento significativo da subjetividade em termos de experiência.

\section{O TEMPO SOCIAL E A EXPERIÊNCIA TRIDIMENSIONAL ENTRE PASSADO, PRESENTE E FUTURO}

O campo de significados que envolve a dimensão simbólica da experiência temporal está atrelado a diversos fenômenos presentes no todo social, os quais fazem que essa percepção se altere. Para Oliva-Augusto² (2002), vivemos um momento em que o passado perdeu o poder de determinar o presente e, ao mesmo tempo, este presente, está tomado por um alargamento que se sobrepõe ao futuro. Logo, as preocupações que pertenceriam ao amanhã invadem a experiência atual, e problemas que antes poderiam ser remetidos a um tempo futuro, penetram no presente. É como se o futuro não pudesse mais oferecer um campo livre para a projeção dos desejos,

\footnotetext{
In: CARVALHO, S. M. S. Quanto o tempo se torna linear. Perspectivas. São Paulo, 9/10: 161-168, 1986/87. In: OLIVA-AUGUSTO, M. H. Tempo, indivíduo e vida social. Ciência e Cultura, Campinas, v. 54, n. 2, out./ dez. 2002. Disponível em: <http://cienciaecultura.bvs. br/pdf/cic/v54n2/14808.pdf >. Acesso em: 2 mar. 2017.
} 
pois cada vez mais se encontra obscurecido e obstruído pelas exigências impostas no presente. Se observarmos algumas das doenças de nosso século, como a depressão, a ansiedade e o estresse, veremos que muitas delas remetem a uma distorção de aspectos relacionados à temporalidade e intensidade. Por isso, a sociedade contemporânea padece de uma notável reconfiguração temporal que acarreta em novas dimensões da experiência tempo-espacial que, por conseguinte, repercutem na instauração de novos modelos de interação e subjetividade. Conforme sustenta Oliva-Augusto (2002), a nossa percepção em relação ao tempo tem sofrido uma dissolução dos elementos que, pelo menos há três séculos, têm constituído a base temporal dos processos sociais. Essa constatação sugere estar em curso uma preocupante ressignificação do tempo que repercute na progressiva desvalorização do passado, na acentuação exagerada do presente, e, por consequência, em um obscurecimento da capacidade de se projetar um futuro.

A progressiva desvalorização do passado vem sendo anunciada por diversos teóricos, entre os quais gostaria de destacar o filósofo Walter Benjamin. Desde Experiência e pobreza (1933), o autor procede à crítica da modernidade ao sustentar que o retraimento da transmissão de experiências - que já vinha ocorrendo desde há muito tempo, entrando em colapso durante a Primeira Guerra Mundial - tem provocado não apenas um distanciamento em relação ao passado, como também tem diminuído a capacidade de uma experiência humana autêntica. Para ele, uma experiência autêntica deve ser compreendida a partir de duas dimensões que trazem o sentido semântico das palavras alemãs Erfahrüng e Erlebnis, em que a primeira se refere a uma dimensão da experiência que abarca um sentido coletivo e histórico (que se acumula, se prolonga e se desdobra ao longo do tempo) e a segunda se relaciona a uma vivência mais individual, fragmentada e cotidiana. Benjamin (1933) afirma que o homem tem se destituído de toda sua herança tradicional e histórica para tornar-se liso, frágil e transparente como um vidro. Assim, o avanço da modernidade estaria reduzindo Erfahrüng à Erlebnis, na medida em que os saberes coletivos - oriundos de vivências e recordações profundas da existência humana - têm sido desprezados em detrimento de vivências individuais, imediatas e de natureza narcísica. ${ }^{3}$ Por isso, todo processo que permite ao ser humano ir se sedimentando no mundo estaria comprometido por essa forma de experiência mais reduzida e empobrecida. Ainda nesse texto, Benjamin sustenta que a experiência se faz da matéria da tradição, pois ela se coloca como um espaço-tempo de um tipo peculiar de saber que se constitui para além do racional.

Uma nova forma de miséria surgiu com esse monstruoso desenvolvimento da técnica, sobrepondo-se ao homem. (...) Pois qual o valor de todo o nosso patrimônio cultural, se a experiência não mais o vincula a nós? A horrível mixórdia de estilos e concepções do mundo do século passado mostrou-nos com tanta clareza aonde esses valores culturais podem nos conduzir, quando a experiência nos é subtraída, hipócrita ou sorrateiramente, que é hoje em dia uma prova de honradez confessar nossa pobreza. Sim, é preferível confessar que essa pobreza de experiência não é mais privada, mas de toda a humanidade (BENJAMIN, 1933, p. 115).

Isso posto, compreendemos que, conforme o mundo moderno foi avançando, o fio condutor que liga o passado ao futuro tornou-se cada vez mais esgarçado, fazendo que os ensinamentos que remetem a uma tradição adquiram o status de ultrapassado e obsoleto. Se tomarmos como referência as antigas sociedades africanas, mais especificamente os impérios sudaneses, os anciãos conhecidos como griots eram pessoas que exerciam certo

O conceito de narcisismo aqui empregado é embasado nas primeiras formações de Freud (1914), porém reinterpretado a partir de abordagens mais contemporâneas, como a de Lasch (1983) e Amaral (1997). 
prestígio e respeito, por guardar e transmitir uma tradição ancestral, relacionada à história e cultura de um povo. A apropriação do passado e o acúmulo de conhecimento eram sinônimos de autoridade e sabedoria. Já nos dias atuais, a palavra passado adquire um tom pejorativo, relacionado a algo antigo, velho, que deve necessariamente ser desprezado ou substituído.

O sistema capitalista global infinito e de contínua mudança nos remete a uma dimensão de tempo que, cada vez mais, tem ignorado o passado para poder se fixar no presente, no novo e no provisório. A crise de autoridade, tão discutida nos dias de hoje, representa, nesse caso, um dos resultados desse processo. Para Hannah Arendt (1979), a noção de autoridade desapareceu desde que o mundo moderno rompeu com suas bases greco-romanas, que trazia como herança a valorização dos ancestrais e das tradições transmitidas de geração em geração. Para essa autora, o conceito de autoridade deve ser compreendido a partir desse processo de transmissão, que traz os ensinamentos apreendidos dos antepassados. Arendt (1979) defende que a crise da autoridade pode ser identificada pelo declínio de suas principais bases de sustentação, que vem ocorrendo desde o século $X X$, com a progressiva evolução da técnica e da ciência, junto ao rompimento da tradição e da religião, identificadas, até então, como pilares fundamentais para o processo de construção e consolidação da História. Para Jamile Borges Silva, o mundo perdeu seus padrões norteadores e agora "as pessoas não sabem mais o que fazer nele e com ele" (2004, p. 190).

A crise de autoridade e a ausência de referências estáveis também revelam efeitos no que diz respeito à constituição da subjetividade. Segundo a teoria psicanalítica, a decadência da figura paterna e o enfraquecimento da instituição familiar acarretam efeitos nos processos identificatórios, na medida em que a sustentação da teoria se baseia na efetivação desses laços afetivos e simbólicos. O lócus fundante da constituição psíquica está voltado para processos que envolvem uma autoridade paterna, um acolhimento materno e identificações parentais projetivas e in- trojetivas. ${ }^{4}$ Quando esses complexos vinculares se encontram enfraquecidos pelo "ethos" social, as bases de sustentação do indivíduo ficam comprometidas em relação à sua inserção futura em outros âmbitos institucionais da sociedade. Christopher Lasch, no livro $A$ cultura do narcisismo (1983), aponta que o homem psicológico do século XX nega o passado e tem dificuldade de enfrentar o futuro, acarretando a perda de significado do próprio presente. Portanto, a falta de conexão entre o que foi e o que está por vir tem propiciado uma experiência no tempo presente destituída de sentido, tornando o indivíduo cada vez mais vulnerável às exigências externas e mercadológicas de um tempo social acelerado e distante das necessidades humanas em termos de subjetividade.

\section{O TEMPO SOCIAL E A EXPERIÊNCIA DA TECNOIMAGEM}

A sociedade contemporânea é marcada por profundas mudanças em um curto espaço de tempo. Embora a história da humanidade seja definida por um processo contínuo de transformação, a questão principal aqui colocada está relacionada aos efeitos da velocidade que as transformações vêm ocorrendo, interferindo substancialmente em nossa percepção do tempo. As mudanças vivenciadas pela geração que nasceu na década de 1980 , por exemplo, que marca o surgimento da internet no Brasil, 5 foram tão intensas e profundas que muitos estudiosos defendem a concepção

\footnotetext{
4 As identificações projetivas e introjetivas são processos psicológicos que permitem ao sujeito assimilar aspectos do outro para a constituição de sua própria personalidade. Para os estudos da psicanálise, a integração social acontece a partir desses fundamentais mecanismos básicos que permitem um processo de distinção e identificação entre elementos externos e internos.

5 Apesar de algumas iniciativas anteriores, um grande projeto que marca o surgimento da internet no Brasil foi datado em 1988, quando a Fundação de Amparo à Pesquisa do Estado de São Paulo (Fapesp), junto à Secretaria Estatal de Ciência e Tecnologia e em parceria com um centro de Pesquisa Americano, inauguram a conexão em rede em nível acadêmico e estatal. Contudo, foi somente a partir da segunda metade da década de 1990 que a internet se tornou acessível para a população.
} 
de uma nova era. ${ }^{6}$ Comparado com todo o processo de mudança que ocorreu durante a Antiguidade e a Idade Média, a revolução digital parece ter acentuado esse processo, impulsionando de maneira radical um novo modo de se comportar, comunicar ou se relacionar com as pessoas e com o tempo. O filósofo tcheco-brasileiro Vilém Flusser (2008) apresenta uma "escala de abstração" para argumentar sobre a subtração dos sentidos nas dimensões espaço-temporais, acarretadas pelas diferentes formas de comunicação que foram desenvolvidas ao longo da História. Suas contribuições apontam para uma perspectiva histórica da linguagem, identificando em cada período um tipo de imagem que medeia comunicação entre o homem e o mundo. Em cada processo de mediação, a escala de abstração se divide em: tridimensional, bidimensional, unidimensional e nulodimensional. Partindo da mais complexa para a mais sintética, cada processo exibe uma dialética interna, que revela perdas e ganhos em termos de experiência.

Para compreender melhor esse processo, retomemos algumas ideias sustentadas pelo comunicólogo alemão Harry Pross: "Toda comunicação humana começa na mídia primária na qual os participantes individuais se encontram cara a cara e imediatamente presentes com seu corpo; toda comunicação humana retornará a este ponto" (PROSS, 1972, 128). A teoria da mídia apresentada por esse autor exibe semelhanças em relação à proposta defendida por Flusser (2008). Ambos exploram os processos comunicativos a partir de uma perspectiva primária do corpo como forma de abstração da experiência. Flusser (2008) argumenta que a versão mais complexa da escala de abstração seria a tridimensional, que permite ao homem uma experiência com o mundo mediada pelo corpo, a partir de dimensões que

6 Nicholas Negroponte (1995) identifica na era digital uma revolução tecnológica diferente da antiga proposta técnica analógica. Pois, enquanto as tecnologias analógicas têm como menor unidade de informação os átomos, as tecnologias digitais têm como unidade os bits, que por meio de combinações lógicas potencialmente infinitas permitem um processamento de dados cada vez mais veloz, com um armazenamento e organização de informações muito mais diversificados e dinâmicos. envolvem altura, largura e profundidade, cujos sentidos podem ser explorados. Conforme a classificação do antropólogo Ashley Montagu (1971), por meio do corpo e da presença é possível experimentar os sentidos de proximidade (tato, olfato e paladar), bem como, os sentidos da distância (audição e visão).

Por sua vez, a comunicação bidimensional ocorre por um processo de mediação estipulado pelas imagens. Para Flusser (2008), a humanidade passou por três movimentos distintos em termos de comunicação - o pré-histórico que se relaciona ao surgimento das primeiras imagens; o histórico em que os textos superaram o predomínio das imagens; e o pós-histórico, que "seria uma espécie de síntese dos precedentes, composto de imagens técnicas ou tecno-imagens" (DUARTE, 2011). Seguindo essa acepção, o primeiro código fundante inventado pela humanidade foram as imagens. A ação de transformar a natureza para satisfazer necessidades primitivas permitiu que o homem superasse o imediato $^{7} \mathrm{e}$ desenvolvesse capacidades de abstração da imaginação para uma forma de pensamento que resultou na mediação pelas imagens. Em contraposição, o plano das imagens desenvolveu um tipo de comunicação bidimensional, na qual se abstraiu a possibilidade de transmissão da profundidade, sendo possível realizar representações apenas em termos de altura e largura. Outro ponto de distinção entre a materialidade tridimensional e a comunicação bidimensional é que, na última, o representante imagético pode estar ausente, ou melhor, não presente de forma concreta. Posteriormente, a comunicação unidimensional foi inaugurada com a invenção da escrita, que surgiu no intuito de transformar o código imagético tradicional em uma estrutura linear que serviria para explicar as imagens, buscando retirar delas seu caráter ilusório e alienante. Para Flusser $\left(1986^{8}\right)$, o ato de escrever des-

O imediato nesse contexto adquire um sentido Hegeliano (1807) sob a luz do conceito de mediação (Vermittlung). Nas suas principais obras, entre elas a Fenomenologia do Espírito (1807), Hegel define o conceito de mediação como um processo dialético, em que, a partir da negação, encontra-se a superação do imediato no mediato.

8 Publicado em Cadernos Rioarte, ano II, n. 5, p. 64-68. Manuscrito Arquivo Flusser, Berlim. 
cola o tempo circular e mágico das gravuras (no qual diversas imagens podem compor ou se sobrepor no mesmo plano) do tempo linear composto por letras que adquirem uma relação causal e sequencial quando colocadas sobre traços, pontos e linhas. Essa forma de comunicação origina o pensamento histórico, conceitual e lógico.

Já na pós-história ou na sociedade pós-industrial, Flusser (2008) identifica um novo predomínio das imagens, porém com um caráter diferente das tradicionais, pois a mediação se dá por meio de aparelhos. Esse novo tipo de imagem, muito diferente dos primórdios, pretende traduzir os códigos lineares evidenciados na escrita, a partir de uma linguagem computacional matemática programada. Trata-se de um "processo circular que retraduz os textos em imagens", porém, sob a forma de imagens técnicas (FLUSSER, 2008, p. 78). Ou seja, as tecnoimagens devem ser reconhecidas como um produto indireto dos textos que possuem uma posição histórica e ontológica diferente das imagens tradicionais. Enquanto as primeiras imagens eram construídas na relação direta entre o homem e a realidade fenomênica, as imagens técnicas são representadas por aparelhos científicos previamente programados por determinados padrões de funcionamento. Destarte, Flusser (2002) faz um alerta em relação ao complexo sistema de virtualidades que compõem o aparelho e que, na maioria das vezes, não são assimiladas por seus operadores, que se encontram submetidos ao fascínio e poder mágico da superficialidade tecnoimagética. $O$ estágio de abstração que se exibe nesse contexto é o mais sintetizável ou nulodimensional da comunicação, pois, a subtração dos sentidos acontece em todos os níveis. As imagens técnicas adquirem o caráter de não apenas representar o real, como se apresentam sendo a própria realidade a partir de modelos ilusoriamente tomados como verdade. A subtração dos sentidos é tão intensa que o corpo vai se desmaterializando no processo de comunicação, não sendo mais capaz de reter a experiência, transitando apenas em sua superfície.

Harry Pross (1972) propõe a teoria dos meios para compreender como os recursos externos no processo comunicativo modificam nossa percepção em termos de experiência. Enquanto que na mídia primária (por meio do corpo) somos capazes de utilizar todos os sentidos em prol da comunicação, na mídia secundária, aqui compreendida como a imagem e a escrita, o homem se utiliza de meios para deixar a marca de "sua presença em sua ausência” (BAITELLO JR., 2014, p. 46). Já na mediação terciária, que se dá por meio da tecnoimagem, é com a inteligência dos próprios aparelhos que passamos a codificar ou decodificar os símbolos. Tanto a mídia secundária quanto a terciária são utilizadas enquanto extensões ou prolongamentos do corpo, capazes de superar as limitações relacionadas ao tempo, espaço e intensidade. Entretanto, embora esses recursos facilitem tais processos, torna-se relevante questionar até que ponto eles subtraem nossos sentidos e capacidade de abstração da experiência. $\mathrm{O}$ status temporal presente em cada mídia se exibe da seguinte forma para Pross (1972): na primária, o tempo se dá no presente em um espaço definido pela presença, enquanto que na mídia secundária o tempo é mais lento, pois o ato de escrever e ler necessita de um processo longo de reflexão, decodificação e apreensão das palavras. Quanto à mídia terciária, o tempo passa de maneira acelerada e o espaço é superado pela virtualidade, já que "se eliminam os problemas espaciais da gravidade e concretude", no qual o real e o virtual atuam simultaneamente (BAITELLO JUNIOR; NAVARRETE, 2017, p. 110).

\section{O DECLÍNIO DA EXPERIÊNCIA NO PROCESSO DE ACELERAÇÃO SOCIAL CONTEMPORÂNEO}

Nesta última parte do ensaio, seguem alguns questionamentos com base nos apontamentos teóricos já apresentados articulados com algumas experiências do cotidiano social. Se tomarmos como referência as afirmações exibidas por Benjamin (1933) - a despeito da experiência autêntica - junto às novas configurações de linguagem e interação social, que trazem consigo a subtração dos 
sentidos e uma aceleração temporal, seguem as perguntas: Que tipo de experiência temos vivenciado em uma sociedade contemporânea cujo ritmo social encontra-se demasiadamente acelerado? Quais os rumos dos processos interacionais, já que nossa experiência tem se tornado cada vez mais empobrecida e destituída de sentido?

Rosa (2010), pensador da Teoria Crítica contemporânea, desenvolveu a Teoria da Aceleração Social, dividindo o fenômeno em três principais categorias: a aceleração técnica, a aceleração das transformações sociais e a aceleração do ritmo de vida. Os "motores propulsores" responsáveis pela aceleração estariam vinculados a ideologias, convicções e crenças que atuam por trás do fenômeno. Levando em consideração esse diagnóstico, cabem algumas reflexões advindas do cotidiano que se articulam com essas categorias.

De modo geral, todas essas acelerações são evidenciadas em diferentes contextos e situações do dia a dia. Quanto ao ritmo de vida, por exemplo, precisa-se admitir que, além da dissolução entre o passado, presente e futuro, encontramo-nos fixados em um tempo presente, cuja experiência do novo, do instantâneo e do provisório não deixa espaço para experiências a longo prazo. A busca intensificada pelo prazer e pela experiência do momento, associada à competividade estimulada pela sociedade capitalista, obriga-nos a um processo contínuo de adaptação às novas exigências do mercado. A sensação que fica é de que a vida é uma constante corrida contra o tempo. E por mais acelerados que estejamos, não conseguimos nos livrar da angústia de que temos pouco tempo para fazer tudo o que precisamos ou desejamos fazer. O ritmo social e o fluxo informacional estão tão intensos que nos tornaram escravos do relógio. $\mathrm{O}$ excesso de informação a circular pelo mundo desperta-nos a sensação de que devemos estar cientes de tudo o que está acontecendo ao nosso redor. A autoridade do passado, antes exercida pelos anciãos, foi transferida para o mercado e sua publicidade, que agora dita ao indivíduo o que se deve consumir, ves- tir, gostar, jogar, desejar e ouvir. Essa autoridade se revela muito potente e sagaz, dada sua característica onipresente na vida cotidiana, que utiliza os recursos tecnológicos para transmitir suas abundantes doses diárias de ofertas e opções de "ser" e "pertencer" no mundo. Rosa (2010) afirma que os efeitos da aceleração social apresentam características relacionadas a um novo formato de dominação totalitária, inclusive mais persuasiva que os regimes políticos ditatoriais vivenciados em outras épocas. Como as normas temporais estão profundamente enraizadas no cotidiano social, o indivíduo destituído de crítica e contextualização histórica torna-se totalmente vulnerável ao ritmo social, concebendo-o como um elemento natural da realidade. Não sendo capaz de distinguir a origem histórica e social desta nova percepção temporal, os fracassos ocasionados por essa lógica são interpretados como uma incapacidade individual de gerenciar o tempo. Baitello Jr. (2010) afirma que na atualidade há espaços apenas para pessoas "fluidas como o vento, evanescentes como a luz e efêmeras como o tempo" (BAITELLO JR., 2010, p. 55). A exacerbada valorização da exposição mediada pelo dispositivo de imagem direciona a experiência individual a um reconhecimento pautado na aparência. O que se aparenta é muito mais estimado do que o ser em essência. Essa retenção da experiência no plano da superficialidade imagética pode ser intensamente observada pelo tempo utilizado com a abundante quantidade de fotos postadas nas redes sociais ou, ainda, pelas ofertas apresentadas por inúmeras agências de turismo, que oferecem pacotes irresistíveis de se conhecer um país, ou até mesmo um continente, em pouquíssimos dias. Nesses casos, o viajante passa a maior parte do tempo, fazendo e desfazendo malas, entrando e saindo de hotéis, aeroportos, carros, ônibus; e quando se chega aos pontos turísticos desejáveis, a principal preocupação do sujeito é virar de costas para a paisagem e tirar a tão esperada self. Assim, toda a energia gasta com bagagens, traslados e correria, é recompensada por uma mala abarrotada de 
produtos, coincidentemente chamados de "lembrancinhas", junto a inúmeras fotografias que revelam poses e imagens desprovidas de experiência.

Sofremos continuamente o achatamento da riqueza subjetiva, com o empobrecimento das trocas que somos capazes de efetuar com o outro; empobrecimento que nos deixa ainda mais perplexos na medida em que, abarrotados de mercadorias, estamos plenamente convencidos de nossa riqueza excepcional (KEHL, 2004).

Constantemente ludibriados por uma imensidão de promessas e slogans, como: Aprenda inglês em 30 dias! Emagreça $3 \mathrm{~kg}$ em dois dias! nossos sentidos vão sendo entorpecidos por máximas que não condizem com a nossa capacidade e limitação humana. Percebemos que a superação espaço-temporal propiciada pelos aparelhos - programados para acelerar os processos, dinamizar o trabalho e flexibilizar as ações - promete economizar um tempo que há muito tempo já não existe mais. A sociedade capitalista pós-industrial, marcada pela supervalorização do trabalho, aproveitou-se dessa nova configuração comunicacional para invadir as esferas privadas do homem contemporâneo. Nesse sentido, fomos obrigados a nos habituar a estar em casa cuidando dos filhos, e, concomitantemente, ter que dividir esse tempo, resolvendo problemas do trabalho. Além disso, a vida das pessoas passou a ser controlada mesmo fora dos postos de serviço. Os processos seletivos, por exemplo, passaram a investigar a história de seus candidatos nas redes sociais e, mesmo depois de contratado, o trabalhador corre o risco de ser demitido, simplesmente porque seu chefe não "curtiu"9 aquela foto postada no domingo à noite. A sociedade contemporânea elevou de uma maneira tão intensa a questão do trabalho e da produção, que já

9 A expressão curtiu faz referência à linguagem cibernética popularmente utilizada. não sabemos mais se trabalhamos para viver ou se vivemos para trabalhar. Sentimos culpa de relaxar e quando temos tempo livre, buscamos insaciavelmente ofertas no mercado que nos deixam ocupados.

A subjetividade contemporânea se produz num ambiente em que os discursos e os signos publicitários articulam o público e o privado de tal modo que a dimensão mais íntima de nosso cotidiano parece estar permanentemente exposto às radiografias televisivas e às campanhas publicitárias. A morada do sujeito contemporâneo não possui mais divisórias, aliás, bem ao estilo do que se vende na televisão, habitamos numa espécie de loft onde não é possível separar o espaço de estar do espaço de evacuar (SILVA, 2004, 190).

\section{CONSIDERAÇÕES FINAIS}

Na tentativa de resgatar no passado alguma direção para as inquietações suscitadas neste artigo, torna-se pertinente conduzir esta conclusão a partir da mitologia grega que nos convoca para duas possibilidades de compreensão do tempo - o tempo de Chronos e o tempo de Kairós. ${ }^{10}$ Representados por duas divindades, eles nos mostram duas possibilidades de experiência temporal. No mito, Chronos pertencia a uma raça de Titãs (a segunda geração de deuses) e era retratado como um ser que devorava os filhos logo que estes nasciam. Esse comportamento revela a característica de um tempo destruidor, que não poupa ninguém. Por receber a profecia de que um de seus filhos iria matá-lo para assumir o seu lugar como senhor da criação, ele buscava eliminar esse perigo, devorando suas crias. Na contemporaneidade, Chronos tem um lugar de destaque, sendo aquele que amedronta e impera, implacavelmente. Muitos são escravizados por

10 In: RIBEIRO, J. C. Vocabulário e fabulário da mitologia. São Paulo: Martins, 1962. 
esse deus e acabam sendo devorados por ele. Vivem sob a tirania das datas e dos prazos e invariavelmente adoecem. Sendo subjugado pela angústia de não dar conta do presente, o homem na atualidade oscila entre a mágoa ou a culpa não elaborada do passado e a ansiedade e o medo do futuro.

Enfim, podemos dizer que o tempo presente nos mostra que a sobrevivência da sociedade, da forma como aprendemos a percebê-la, está ameaçada e a única proposta de reversão possível desse processo encontra-se na compreensão da segunda divindade mitológica de tempo, chamada Kairós. Ao contrário de Chronos, Kairós, simboliza um tempo subjetivo, ou seja, um tempo concebido pela percepção de cada um. É o tempo que nos permite estar sensível à eternização de um momento e que nos dá forças para dizer basta ao que acreditamos ser pura perda de tempo. É o tempo que nos liberta do relógio e nos reconecta à subjetividade humana. $\mathrm{Na}$ mitologia, também significa a identificação do momento oportuno. Nesse sentido, talvez este seja o momento adequado de reestabelecer velhos padrões afetivos de relacionamento humano, de se reconectar com alguns aspectos importantes da tradição esquecida e de retomar o elo entre o passado, o presente e o futuro, de modo que, a consciência do momento presente não carregue os fardos do passado nem sofra por antecipar as ansiedades do futuro. Para Rosa (2010), uma vida livre da alienação imposta por Chronos seria aquela que se mostra equilibrada em atingir experiências que provoquem ressonância com o mundo. Para os gregos, Kairós era a única força capaz de enfrentar, lutar e vencer Chronos. Assim, a crise vivenciada por este tempo só poderá ser superada quando o indivíduo contemporâneo encontrar em Kairós a conexão perdida consigo e com a dimensão de sua experiência autêntica.

\section{REFERÊNCIAS}

AMARAL, M. O espectro de Narciso na modernidade: de Freud a Adorno. São Paulo: Estação Liberdade, 1997, $189 \mathrm{p}$.

ARENDT, H. Entre o passado e o futuro. Tradução de Mauro W. Barbosa, 5. ed. São Paulo: Perspectiva, 1979, $348 \mathrm{p}$.

BAITELLO JUNIOR, N. A era da iconofagia: reflexões sobre a imagem, comunicação, mídia e cultura. São Paulo: Paulus, 2014.

. A serpente, a maçã e o holograma. São Paulo: Paulus, 2010, 120 p.

BAITELLO JUNIOR, N.; NAVARRETE, H. M. C. Escola, tablet e vínculos sociais. Revista Latinoamericana de Ciências de la Comunicación, São Paulo, v. 14, n. 26, 2017. Disponível em: <https:// www.alaic.org/revista/index.php/alaic/article/view/921/466>. Acesso em: 25 out. 2017.

BENJAMIN. W. Experiência e pobreza. In: . Magia e técnica, arte e política: ensaios sobre literatura e história da cultura. Tradução de Sérgio Paulo Rouanet, 7. ed. São Paulo: Brasiliense, 1994 [s. p.].

BUCCI, E.; KEHL, M. R. Videologias: ensaios sobre televisão. São Paulo: Boitempo, 2004, 252 p.

CARVALHO. S. M. S. Quanto o tempo se torna linear. Perspectivas, São Paulo, v. 9/10, p. 161-168, 1986/87. Disponível em: <http://seer.fclar.unesp.br/perspectivas/article/view/1868/1535>. Acesso em: 4 fev. 2018.

DUARTE, R. Indústria Cultural: uma introdução. Rio de Janeiro: Editora FGV, 2010,. 129 p.

. A plausibilidade da pós-história no sentido estético. Trans/Form/Ação, Marília, v. 34, 
número especial, p. 155-180, 2011. Disponível em: <http://www2.marilia.unesp.br/revistas/index. php/transformacao/article/download/1160/1036>. Acesso em: 28 out. 2017.

ELIAS, N. Sobre o tempo. Rio de Janeiro: Jorge Zahar, 1984, 165 p.

FLUSSER, V. Texto/imagem enquanto dinâmica do Ocidente. Revista Caderno Rioarte, ano II, n. 5, p. 64-68, jan. 1996.

. Filosofia da caixa preta: ensaios para uma futura filosofia da fotografia. Rio de Janeiro: Relume Dumará, 2002, 82 p. (Conexões).

2008, $150 \mathrm{p}$.

. O universo das imagens técnicas: elogio da superficialidade. São Paulo: Annablume,

LASCH, C. A cultura do narcisismo. Rio de Janeiro: Imago, 1983, 320 p. [Traduzido do original em inglês The Culture of Narcisism, 1979].

MARTINS, J. C. O. et al. De Kairós a Kronos: metamorfoses do trabalho na linha do tempo. Cadernos de Psicologia Social do Trabalho, São Paulo, v. 15, n. 2, p. 219-228, dez. 2012. Disponível em: <http://pepsic.bvsalud.org/pdf/cpst/v15n2/v15n2a05.pdf>. Acesso em: 2 mar. 2017.

MONTAGU, A. Tocar: o significado humano da pele, 7. ed. São Paulo: Summus, 1971, 427 p. (Novas buscas em psicoterapia, 34).

NEGROPONTE, N. A vida digital. São Paulo: Companhia das Letras, 1995, 210 p.

OLIVA-AUGUSTO, M. H. Tempo, indivíduo e vida social. Ciência e Cultura, Campinas, v. 54, n. 2, out./dez. 2002. Disponível em: <http://cienciaecultura.bvs.br/pdf/cic/v54n2/14808.pdf>. Acesso em: 2 mar. 2017.

PROSS, H. Medienforschung: Film, Funk, Presse, Fernsehen. Darmstadt: Habel, 1972, 303 p.

RIBEIRO, J. C. Vocabulário e fabulário da mitologia. São Paulo: Martins, 1962, 339 p.

ROSA, H. Alienation and acceleration: towards a critical theory of late-modern temporality. Aarhus: Aarhus University Press, 2010, 111 p.

SILVA, J. B. Berçários de cinismo: mídia e identidade na contemporaneidade. Revista da Faced, Salvador, n. 8, p. 187-193, 2004. Disponível em: <https://portalseer.ufba.br/index.php/entreideias/article/view/2823/2000>. Acesso em 20 nov. 2017.

\section{SOBRE A AUTORA}

\section{ELAINE MORAES SANTOS}

Doutoranda em Educação pela Universidade de São Paulo (USP), Mestra em Educação Escolar pela UNESP de Araraquara e graduada em psicologia pela Universidade Metodista de Piracicaba (2009). Atuação na área da psicologia e educação, com ênfase em psicologia social.

elainecms@usp.br

Recebido em: 03/11/2017

Aprovado em: 26/03/2018 